\title{
Applied pressure reduced perceived pain at the intramuscular injection site
}

Source of funding: not stated.

For correspondence: DrJ W Chung, The Hong Kong Polytechnic University, Kowloon, Hong Kong, China. hsjchung@ inet.polyu.edu.hk

\section{QUESTION: In participants receiving intramuscular vaccination, does the application of manual pressure decrease the amount of pain perceived?}

\section{Design}

Randomised \{allocation concealed*\}†, unblinded,* controlled trial with follow up immediately after injection.

\section{Setting}

An active immunisation programme at a Hong Kong University

\section{Participants}

74 participants between 18 and 42 years of age (mean age $21 \mathrm{y}, 55 \%$ women) who were participating in an immunisation vaccination campaign (convenience sample) and were university students of Chinese ethnic origin, able to read Chinese and communicate in Cantonese with no known history of special pain syndrome (eg, hyperalgesia and allodynia) were included. Follow up was $100 \%$.

\section{Intervention}

The left and right arms of the participants (intrasubject comparison) were randomised to receive an intramuscular injection of hepatitis A and hepatitis B vaccine with (intervention condition) and without (control condition) the application of pressure at the injection site. A mechanical pressure detection device was placed between the participant's arm and the investigator's thumb. Manual pressure was applied in a standardised way to the deltoid region of the participant's arm for 10 seconds prior to the delivery of vaccination.

\section{Main outcome measure}

Pain intensity measured by the 10 point Pain Intensity Verbal Rating Scale (Cantonese) $(0=$ no pain).

\section{Main results}

The mean pain score was lower among patients who received manual pressure prior to injection (table). Women scored higher for perceived pain intensity for both the intervention $(\mathrm{p}<0.001)$ and control conditions $(\mathrm{p}<0.001)$. The mean pressure recorded by the detection device was $190.82 \mathrm{~mm} \mathrm{Hg}$. The maximum pressure that the device could detect was $200 \mathrm{~mm} \mathrm{Hg}$, and 29 readings were measured at $200 \mathrm{~mm} \mathrm{Hg}$.

\section{Conclusion}

In patients receiving a vaccination, applied pressure at the intramuscular injection site reduced the amount of perceived pain.

*See glossary.

$\dagger$ Information provided by the author.
Applied pressure at the injection site v no applied pressure in adults receiving hepatitis A and $B$ vaccinations

\begin{tabular}{lllll}
$\begin{array}{c}\text { Outcome after } \\
\text { injection }\end{array}$ & $\begin{array}{l}\text { Applied } \\
\text { pressure } \\
\text { (mean, SE) }\end{array}$ & $\begin{array}{l}\text { No applied } \\
\text { pressure } \\
\text { (mean, SE) }\end{array}$ & $\begin{array}{l}\text { Mean pain } \\
\text { reduction } \\
(95 \% \mathrm{CI})\end{array}$ & $\begin{array}{l}\text { Mean relative } \\
\text { pain reduction }\end{array}$ \\
\hline $\begin{array}{l}\text { Pain perception } \\
(0=\text { no pain, } \\
10=\text { crucifying } \\
\text { pain) }\end{array}$ & $1.77(0.17)$ & $2.87(0.18)$ & $1.1(1.06$ to 1.13$)$ & $38 \%$ \\
\hline
\end{tabular}

Data provided by the author

\section{COMMENTARY}

More than 12 billion intramuscular (IM) injections are given annually throughout the world. ${ }^{1}$ Any change in IM injection procedure would have a substantial effect and should be considered cautiously. The article by Chung $e t$ al, however, provides compelling evidence that manual pressure applied to the injection site does reduce pain.

The usefulness of the procedure, however, remains in question. Though physicians have a duty to minimise their patients' discomfort in any feasible way, such benefits must be weighed against potential risks. Before implementation of this technique, for instance, it should be confirmed that it does not produce adverse effects (eg, pain hours or days after injection, reduction in the effectiveness of vaccines). Other techniques used to minimise the pain of IM injections have been subject to such scrutiny. ${ }^{2}$

In most adults, IM injections are not particularly painful, whether or not manual pressure is applied. This technique, therefore, may be more useful in populations highly sensitive to pain, such as children. Other modalities have proven useful in reducing pain before injections in children, such as the EMLA (Eutectic Mixture of Local Anaesthetics) patch, ${ }^{3}$ but the manual pressure technique is faster and cheaper.

Chung et al therefore provide evidence that can form the background for further study. In addition to studying adverse effects and possible benefits to children, future investigators could explore variation in the type, strength, and duration of pressure used.

There are 2 aspects of the methodology that raise concern. Firstly, the authors do not state how they controlled for possible differences in pain due to the different chemical constituents of the hepatitis A and hepatitis B vaccines. Administering one of the vaccines more often in the experimental arm could have biased the results. Secondly, there is no way to blind this study since subjects will always know which arm was the experimental arm.

Brian Primack, MD, EdM University of Pittsburgh School of Medicine Pittsburgh, Pensylvania, USA

1 Nicoll LH, Hesby A. Intramuscular injection: an integrative research review and guideline for evidence-based practice. Appl Nurs Res 2002;15:149-62.

2 Halperin BA, Halperin SA, McGrath P, et al. Use of lidocaine-prilocaine patch to decrease intramuscular injection pain does not adversely affect the antibody response to intramuscular injection pain does not adesely diphtheria-tetanus-acellular pertussis-inactivated poliovirus-Haemophilus influenzae type b conjugate and hepatiti

3 Cassidy KL, Reid GJ, McGrath PJ, et al. A randomized double-blind, placebo-controlled Cassidy KL, Reid GJ, McGrath PJ, et al. A randomized double-blind, placebo-controlled
trial of the EMLA patch for the reduction of pain associated with intramuscular injection trial of the EMLA patch for the reduction of pain associated with
in four to six-year-old children. Acta Paediatr 2001;90:1329-36. 